\title{
Inter Tester and Intra Tester Reliability of Three Diagnostic Tests to Determine Pelvic Girdle Pain Over Second Trimester in Pregnancy
}

\author{
Jaskiran Kaur ${ }^{1}$, Ponmathi P $^{2 *}$ and Sivakumar VPR ${ }^{3}$ \\ ${ }^{1}$ Women Health Physiotherapist, India \\ ${ }^{2}$ Assistant Professor, SRM College of Physiotherapy, SRM Institute of science and Techology, India \\ ${ }^{3}$ Former Dean, SRM College of Physiotherapy, SRM Institute of science and Techology, India
}

Submission: August 16, 2018; Published: September 07, 2018

"Corresponding author: Ponmathi P, Assistant Professor, SRM College of Physiotherapy, SRM Institute of science and Techology, Kattankulathur, India; Email: ponmathi_sugadev@yahoo.co.uk

\author{
Abstract \\ Introduction: Pelvic girdle pain during pregnancy is considered as tenderness/pain in the lower back,Pelvic region and Symphysis with \\ or without radiation to Pubic, Groin and Inner thigh.
}

Aim: To assess the inter tester and intra tester reliability of three diagnostic tests to determine Pelvic Girdle Pain over second trimester in pregnancy and severity of its complaints.

Methodology:This is a non experimental study, Observational type to find out the Intertester and intra tester reliability of three diagnostic tests. In this study, Thumb-Posterior Superior Iliac Spine test, the heel bank test, and the abduction test are examined for both groups A with Pelvic Girdle Pain and B without Pelvic Girdle Pain.

Results: The percentage of agreement (47.5) was lowest in the group B of pregnant women without Pelvic Girdle Pain. Heel bank test for left and right sides for both Group A and Group B subjects seemed to show a good Intertester reliability ( $\mathrm{k}=0.8)$.

Conclusion: Among these three tests heel bank test shows good Intertester and Intratester reliability for both the sides.

Keywords: Inter tester; Intra tester; Pelvic girdle pain; Posterior iliac spines; Sacroiliac joint; Diagnostic tests; Pregnancy; Musculoskeletal disorder

Abbreviations: PGP: Pelvic girdle pain; PSIS: Posterior Iliac Spines; SIJ: Sacroiliac Joint

\section{Introduction}

Pelvic Girdle Pain (PGP) is frequently reported musculoskeletal disorder in pregnant women.Pelvic girdle pain during pregnancy is considered as tenderness/pain in the lower back,Pelvic region and Symphysis with or without radiation to Pubic, Groin and Inner thigh. Increased pain commonly occurs during normal activities such as walking, parting or lifting the legs, difficulty in turning in bed, abducting the legs or getting dressed [1].

Various scientific studies shows that about $25 \%$ to $76 \%$ of all pregnant women experience Pregnancy related Pelvic Girdle Pain [2]. Pelvic girdle pain prevent them from performing household activities and employment activities [3].

Hormonal,Mechanical causes are the most commom cause for developing pelvic girdle pain possible cause for developing pelvic girdle pain (PGP) during pregnancy could be an asymmetry in position and movement of pelvic bones. Right and left half of the pelvic bones are in rotated position with regard to the sacrum which could be caused by asymmetric muscle tone. Therefore the Posterior iliac spines (PSIS) do not align in the standing or sitting positions which results in Pelvic Girdle Pain.

In Physiotherapy practice, Pelvic Girdle Pain is mostly diagnosed by recording the Patient history and Physical examination. No universal examination tests are followed to assess Pelvic Girdle Pain in pregnancy as there is a lack of a reliable test.

Several studies on the diagnosis of Pelvic Girdle Pain have investigated the intra and Intertester reliability of palpatory and movement tests of the Sacroiliac Joint (SIJ) and show low reliability [4]. 
There arises a need for reliable and simple specific test to determine Pelvic Girdle Pain. So this study is designed to assess the inter tester and intra tester reliability of three diagnostic tests to determine Pelvic Girdle Pain over second trimester in pregnancy and severity of its complaints.

\section{Methodology}

This is a non experimental study, Observational type to find out the Intertester and intra tester reliability of three diagnostic tests. Both primi and multipara women aged 20-35 years with a report of pelvic girdle pain in their second trimester are included in this study. Women of High risk pregnancy,sciatica are excluded from the study. 40 subjects who had satisfied the inclusion and exclusion criteria are selected from IQBAL Nursing Home and Hospital, Ludhiana, Punjab.

Consent form was obtained from them and procedure of the study and safety of the test were explained in detail to the subjects.

The subjects were made comfortable and the subjects were assessed with Quebec Back Pain Scale (Annexure-3) and antenatal assessment chart (Annexure-2). According to pain, subjects were divided into groups group A with pelvic girdle pain and group B without pelvic girdle pain. Painful area was marked on body chart. The severity of pain was measured by 11 points point numerical pain rating scale.

In this study, Thumb-Posterior Superior Iliac Spine test, the heel bank test, and the abduction test are examined for both Groups A with Pelvic Girdle Pain and Group B without Pelvic Girdle Pain.

\section{Thumb-posterior superior iliac spine test}

The starting position of the subjects was an actively upright sitting position, on a level surface, with arms crossed. The examiner was seated on a stool and the position of the caudal aspect of the Posterior Superior Iliac Spine (PSIS) was palpated with moderate pressure (Figure 1). The relative position of the Posterior Superior Iliac Spine was scored.

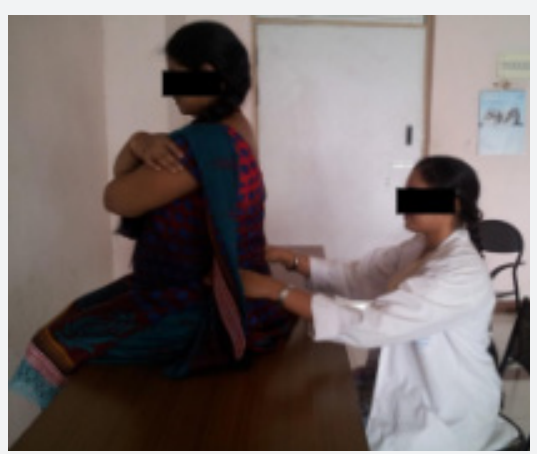

Figure 1: Thumb Posterior Superior Iliac Spine test

\section{Click-clack movement}

In the same starting position as above, the subjects moved the pelvis actively, first forward and then followed by backward rotation (from lordosis to kyphosis). The speed of each Posterior Superior Iliac Spine covering this "route" is documented with the thumb and the click-clack movement was positive if one of the Posterior Superior Iliac Spine moved slower from cranial to caudal.

\section{Heel bank test}

The position of the subjects and the therapist is same as above. The subjects were asked to raise the left knee and place the heel on the bench without using hands and the same procedure was carried out with the right

The ability to raise the leg was scored on a 5-point scale:

$0=$ no effort

$1=$ little effort

$2=$ moderate effort

$3=$ severe effort

$4=$ unable.

Score 0 was considered as negative and scores 1 to 4 as positive.

\section{Abduction test}

The test was performed in the side-lying position, both hips in $\pm 70^{\circ}$ flexion and both knees in $\pm 90^{\circ}$ flexed position. The examiner was standing behind the subjects, who was asked to raise the upper leg about $20 \mathrm{~cm}$ in abduction. The subjects then turned over to the other side and performed the same movement.

The ability to lift the leg was scored on a 5-point scale:

$0=$ no effort

$1=$ little effort

$2=$ moderate effort

$3=$ severe effort

$4=$ unable

Score 0 was considered as negative and scores 1 to 4 as positive.

Two physiotherapists tested the subjects independently. Primary physiotherapist tested subjects twice at one hour gap.

\section{Results}

\section{Intratester reliability (Table 1)}

Primary physiotherapist tested all the study subjects twice for all three tests. The results are presented in Table 2. The $\mathrm{K}$ values of the tests were calculated for every group. They varied from 0.78 to 1 .

The heel bank test for left and right sides for both Group A and Group B subjects seemed to show a high Intratester reliability (K=0.86). In Thumb-Posterior Superior Iliac Spine test 
only palpation test showing good reliability in Group A subjects ( $\mathrm{K}=0.89)$. In Abduction test, only left side shows a high Intratester reliability for both Group A and Group B Subjects.

Table 1: Sociodemographic data of the subjects participating in the study.

\begin{tabular}{|c|c|c|}
\hline & Group A with Pelvic Girdle Pain (n=20) & Group B Without Pelvic Girdle Pain (n=20) \\
\hline & Mean (SD) & Mean (SD) \\
\hline Age & $26.55(3.4)$ & $18.55(3.1)$ \\
\hline Gestational age(weeks) & $18.95(3.9)$ & $1.35(0.6)$ \\
\hline Number of pregnancies & $1.45(0.7)$ & 2 \\
\hline PGP in previous pregnancy & 4 & $11.55(1.9)$ \\
\hline QBPDS score (range 0-100) & $36.25(4.9)$ & \\
\hline
\end{tabular}

PGP: Pelvic Girdle Pain

QBPDS: Quebec Back Pain Disability Scale.

Table 2: Intratester reliability.

\begin{tabular}{|c|c|c|}
\hline & Group A with Pelvic Girdle Pain & Group B Without Pelvic Girdle Pain \\
\hline Thumb PSIS test & $0.89(95 \%)$ & -0.475 \\
\hline Click clack movement & -0.9 & $0.828(47.5 \%)$ \\
\hline Heel bank test Lt & $0.86(90 \%)$ & $0.835(47.5 \%)$ \\
\hline Heel bank test Rt & $0.78(85 \%)$ & $1(50 \%)$ \\
\hline Abduction test Lt & $1(100 \%)$ & $1(50 \%)$ \\
\hline Abduction test Rt & -0.8 & $-47.50 \%$ \\
\hline
\end{tabular}

\section{Intertester reliability (Table 3)}

Table 3: Intratester reliability.

\begin{tabular}{|c|c|c|}
\hline & Group A with Pelvic Girdle Pain & Group B Without Pelvic Girdle Pain \\
\hline Thumb PSIS test & $0.6(80 \%)$ & -0.475 \\
\hline Click clack movement & $-90 \%$ & $0.68(47.5 \%)$ \\
\hline Heel bank test left & $0.79(85 \%)$ & $0.83(47.5 \%)$ \\
\hline Heel bank test right & $0.8(85 \%)$ & $0.62(50 \%)$ \\
\hline Abduction test left & $0.81(85 \%)$ & -0.5 \\
\hline Abduction test right & $-90 \%$ & -0.475 \\
\hline
\end{tabular}

Two physiotherapist tested all the study subjects for all three tests. Thumb Posterior Superior Iliac Spine test palpation shows $\mathrm{k}$ value of 0.6 which interpret moderate Intertester reliability among Group A subjects.

Heel bank test for left and right sides for both Group A and Group B subjects seemed to show a good Intertester reliability $(\mathrm{k}=0.8)$. Abduction test for left side for Group A also showing good Intertester reliability $(\mathrm{k}=0.81)$.

\section{Discussion}

In previous days, Pelvic Girdle Pain is mostly diagnosed by recording the patient's history and physical examination. Examination tests are used in minimal to show irregularities in position and mobility of Sacroiliac Joint. No universal examination tests are followed to assess Pelvic Girdle Pain in pregnancy, as there is lack of reliability.

The statistical results of this study shows the percentage of agreement is low for group B without Pelvic Girdle Pain (47.5\%) as compared to group A with Pelvic Girdle Pain (90\%), so we can use these tests to diagnose of pelvic girdle pain.
Thumb-Posterior Superior Iliac Spine test part of the test done in sitting position shows moderate reliability $(\mathrm{K}=0.6)$. But for click clack test $\mathrm{K}$ value could not be calculated because during second reading and second therapist marked positive for all the subjects.

Heel bank test left and right shows good reliability ( $\mathrm{K}=0.8)$ and Abduction test only left side shows the good reliability $(\mathrm{k}=1)$. This statistical analysis infers that all the above mentioned tests seemed to have high percentage of positive agreement between the therapist, thus good intrarater relaibility is found.

The percentage of agreement (47.5) was lowest in the group B of pregnant women without Pelvic Girdle Pain. This statistical analysis infers that all the above mentioned tests seemed to have high percentage of positive agreement between the therapists in Group A (90\%) subjects.

\section{Conclusion}

Among these three tests, Heel bank test have the good Intertester and Intratester reliability. Although Heel bank test is fully subjective, the therapist could feel the movement during the 
test. It shows high significance and can be implicated for clinical practice.

\section{References}

1. Vleeming A, Albert HB, Ostgaard HC, Stuge B, Sturesson B (2008) European guidelines on the diagnosis and treatment of pelvic girdle pain. In: Cost action low back pain: guidelines for its management. Eur Spine J 17(6): 794-819.
2. Pierce H, Homer CS, Dahlen HG (2012) Pregnancy related lumbopelvic pain: listening to Australian women. Nursing Research and Practice 2012: 387428.

3. Pohjahanen AI, Mogren IM (2008) Physical activity and persistent low back pain and pelvic pain post partum. BMC Public Health 8: 417.

4. Anneke M, Cobelens VK (2008) Pregnancy-related pelvic girdle pain: Intertester reliability of 3 tests to determine asymmetric mobility of the sacroiliac joints. Manipulative and Physiological Therapeutics J 31(2): 130-136.

\section{Your next submission with Juniper Publishers will reach you the below assets}

- Quality Editorial service

- Swift Peer Review

- Reprints availability

- E-prints Service

- Manuscript Podcast for convenient understanding

- Global attainment for your research

- Manuscript accessibility in different formats ( Pdf, E-pub, Full Text, Audio)

- Unceasing customer service

Track the below URL for one-step submission _. https://juniperpublishers.com/online-submission.php 